\title{
Elderly and Clothing: Considerations about Handling Trimmings
}

\author{
Neves Érica Pereira das*, Marteli Letícia Nardoni and Paschoarelli Luis Carlos \\ School of Architecture, Arts and Communication, PPG Design - Postgraduate Program in Design, São Paulo State University (UNESP) - Bauru, Brazil
}

Submission: November 08, 2017; Published: January 12, 2018

*Corresponding author: Neves Érica Pereira das, School of Architecture, Arts and Communication, PPG Design - Postgraduate Program in Design, São Paulo State University (UNESP) - Bauru, Brazil, Email: ericapneves@yahoo.com.br

\begin{abstract}
The aging population is a growing reality around the world and has contributed to intensify discussions and investigations within the scientific field of several areas of knowledge. In the Design scope. the new population demand determines new consumption patterns that are characterized by the requirement for products and services which are appropriate for needs and expectation of these individuals Given this reality, the present study, through a bibliographical survey, aimed to discuss some physical aspects characteristic of aging, especially regarding hands and fingers, which can influence the handle of trimmings devices during the act of dress and undress of elderly users. It was noticed that research on the quality of interaction between elderly individuals and the different types of trimmings is essential for understanding the difficulties caused due the loss of functional movements of hands and fingers as well as the declining sensitivity in these areas during aging.
\end{abstract}

Keywords: Aging; Trimmings; Clothing; Ergonomics

\section{Introduction}

Aging is a complex phenomenon involving physiological, biochemical, psychological and cognitive changes. It is a natural and progressive process that occurs in different ways and rhythms in each individual, which are influenced by factors such as lifestyle, socioeconomic conditions, chronic diseases, cultural environment, among others.

The increase of elderly population in the world, especially in developed countries, has contributed to intensify discussions and investigations within the scientific field of several areas of knowledge. In the scope of Design, the new population demand determines new consumption patterns that are characterized by the requirement for products and services that are appropriate for needs and expectation of these individuals. These specificities are associated not only with changes in taste and subjectivities, but also with physical and cognitive changes consequential of this stage of life.

Among the physical alterations, the biomechanical variables stand out, which, given the restrictions and motor losses that occurred during the aging process, are essential for the assertive and adequate design of products destined to the elderly user. With regard to the fashionable product, more specifically the clothing, the configurational patterns of the pieces, associated with this physical condition, influence the ability and capacity of elderly of perform daily tasks, such as dressing and undressing. Therefore, considerations about physical properties attributed to clothing and the understanding of physical limitations of elderly are essential to the development of products that can guarantee the autonomy of the user as well as promote comfort and safety.

Among the clothing components, the trimmings - little devices used to enable the opening and the closing of clothing, such as buttons, zippers and velcro - are worth to stressing. These devices, due its reduced size and physical composition, can have difficulty to be handle by the elderly individual, once such users can present vision problems as well as decreased handle ability and loss of hand dexterity.

Given this reality, the present study, through a bibliographical survey, aimed to discuss some physical aspects characteristic of aging, especially regarding hands and fingers, which can influence the handle of trimmings devices during the act of dress and undress of elderly users. Besides that, it seeks to identify ergonomics and usability aspects which are important for the development of clothing products intended for this public.

\section{Elderly user and trimmings: Handling characteristics}

The stages of clothing elaboration are essentially based on: project planning and development (knowledge about the target public, trends, new technologies); creation stages (brainstorming, material survey); development and evaluation of prototypes (modeling and sewing; fabric and trimmings; finishes, and others); and, production of the final product. 
The accomplishment of such steps aims at the construction of quality products that can provide well-being to the users. For this, all product development must be user-centered, identifying and determining assertive dimensions and parameters that are consistent with their needs, capacity and limitations.

Clothing is part of the daily life of individuals and is concerned with the tasks of dressing and undressing. The achievement of these activities involves corporal movements that are associated to coordination, balance, force and amplitude. Particularly for the elderly, these activities can generate discomfort or embarrassment, given the difficulties of accomplishment due to the motor restrictions.
Among the difficulties faced, it is evident the problematic about the handling of the trimmings (Figure 1), which consist in devices that allow the opening and closing of the pieces. These are considered completion elements of a garment, and are characterized by being interactive and functional. They are important components that influence the usability perception of the clothing as well as the experience of use, since it is by them that the parts (pieces) of the textile structures are attached. Moreover, depending on their material properties as well as their arrangement in the piece, they can be perceived by users as an element of aesthetic differential.

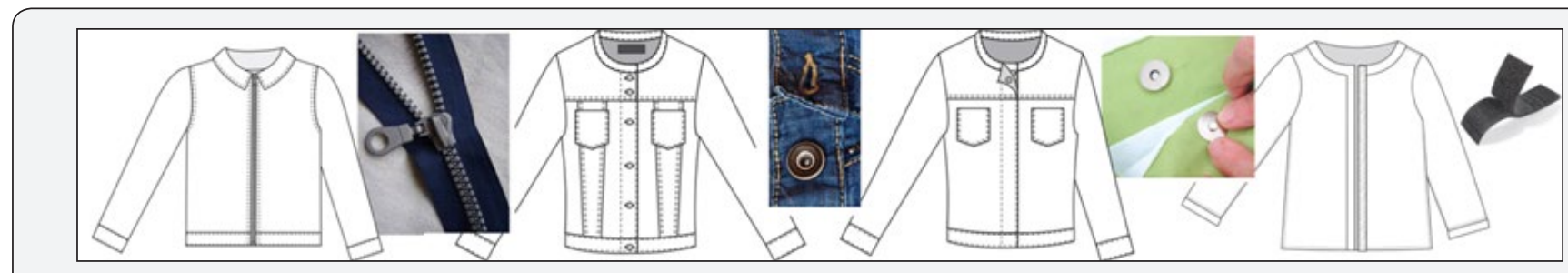

Figure 1: Trimmings and applications: zíper; bottons; vecro.

its manipulation requires manual coordination and dexterity, which can be an obstacle to the elderly user, once the aging process has a degenerative effect on hand function. This process is characterized by declines in hand and finger strength and ability to control pinch force and maintain a steady precision pinch posture, manual speed, and hand sensation [1].

This condition leads to lack of independence in Activities of Daily Living (ADLs)-such as dress and undress - and implies in other difficulties in performing basics tasks such as tying shoelaces, manipulating earrings, writing, fastening buttons, among others [2].

Spirduso [3] reports that for an 85-year-old individual, buttoning a blouse, something that was previously achieved without conscious thought, has become a challenging task that requires considerable attention and energy. This is because the trimmings, such as the buttonhole button, require hands coordinated movements, as well as grasping strength, manual dexterity and torque movements, skills affected by the advancing age.

Snap buttons may also present some difficulties, once it requires fingers pressure, and hand and wrist forces. The finishing of these buttons also influences the way it is handled, requiring finger sensitivity. According to [4] in general, the circular objects, or those that have very smooth superficial finishing, are less effective because usually require greater forces.

That way, the loss of sensitivity as well the hand force declining of elderly can lead to difficulties during the manipulation of such devices. In addition, as state [5], the elderly fingers tend to be smoother and, therefore, slippery, requiring even more grip strength. According to the authors, this condition is due mainly to age-related changes in skin properties, and cutaneous sensibility functions, and in part to central nervous system function. The same is affirmed by Cole [6] that also argues that the excessive grasp forces in elderly individuals represent a strategic response to tactile sensibility impairment.

\section{Ergonomics and third age: contributions for trimmings development}

Elderly users tend to be more affected regarding products that do not have properties consistent with their physical and cognitive limitations, which implies difficulties in interaction. This condition, consequently, can generate embarrassments and discomfort to the user, what can cause a negative experience of using.

Given this, the application of ergonomics and usability principles during the development of products for the elderly is essential, since such sciences focus on the user and on the quality of interactivity that him maintains with a certain product. Meet the ergonomic guidelines maximizes the chances of a positive user experience that generate well-being, comfort and safety. Besides that, as argue [7], ergonomics provides subsidy for the analysis of specific profiles of elderly users and their interaction with a particular product, task or environment.

This kind of knowledge is essential for the produce design, especially with regarding of objects used in daily tasks, such as clothing and, consequently, fasteners. Given this, the information about the elderly body limitations must guide the guidelines of all kind of products. In case of the fasteners, as previously shown, some particularities involving some physical losses such as the decline of grip force, the limitations with the pinch movement, and/or the reduction of fingers sensitivity, is important to generate parameters and solutions that must be applied in this kind of device. 


\section{Discussions and Considerations}

Research on the quality of interaction between elderly individuals and the different types of trimmings is essential for understanding the difficulties caused due the loss of functional movements of hands and fingers as well as the declining sensitivity in these areas during aging.

The functions of opening and closing garments, possible by the trimmings, is part of the dressing and undressing tasks, which are recurring activities in the routine of individuals. Since such actions are perceived as difficult by the elderly user, a sense of embarrassment and incapacity is generated, even determining the loss of the autonomy of such an individual.

Therefore, ergonomics, when applied to design practices, can contribute to the generation of devices that are suitable for the elderly user, helping them to perform dressing and undressing tasks autonomously. In this case, the understanding of the movements during the manipulation of the trimming is essential to obtain information regarding the possible problems that can be generated due to the physical limitations of aging.

The comprehension of this interaction generates important variables for the correct dimensioning of trimmings that are adequate to the physical and cognitive needs of the elderly, promoting a feeling of inclusion and well being. Besides that, it is important to investigate materials and finishes that contribute with the easy handle of the device, avoiding, for example, smooth and slippery ones. Given this, further studies about this interaction, mainly focusing on the hand manipulation aspects of the devices, including forces, grip, sensitivity, and others, is suggested, in order to increase the inclusion of these users.

\section{References}

1. Ranganathan VK, Siemionow V, Sahgal V, Yue GH (2001) Effects of Aging on Hand Function. J Am Geriatr Soc 49(11): 1478-1484.

2. Shiffman LM (1992) Effects of Aging o Adult Hand Function. Am J Occup Ther 46(9): 785-792.

3. Spirduso WW (2005) Dimensões físicas do envelhecimento. Barueri: Manole.

4. Razza BM, Paschoarelli LC, Lucio CC (2009) Forças manuais e o design de produtos: uma revisão. Revista Tecnológica, 18(1): 37-51.

5. Kinoshita H, Francis PR (1996) A comparison of prehension force control in young and elderly individuals. Eur J Appl Physiol Occup Physiol 74(5): 450-460.

6. Cole KJ (2010) Grasp Force Control in Older Adults. J Mot Behav 23(4): 251-258.

7. Neves EP (2015) Biomechanics and Fashion: Contributions for the Design of Clothing for the Elderly. Procedia Manufacturing, Elsevier 3: 6337-6344. 